\title{
Physical disturbance by kelp abrades erect algae from the understorey
}

\author{
Andrew D. Irving ${ }^{1,2, *}$, Sean D. Connell ${ }^{1}$ \\ ${ }^{1}$ Southern Seas Ecology Laboratories, School of Earth and Environmental Sciences, DP 418, University of Adelaide, \\ Adelaide, South Australia 5005, Australia \\ ${ }^{2}$ Present address: Ecology and Evolutionary Biology, Box G-W, Brown University, Providence, Rhode Island 02912, USA
}

\begin{abstract}
Positive and negative interactions among organisms are key determinants of pattern in the distribution and abundance of many species. Beneath subtidal canopies of kelp Ecklonia radiata (Laminariales), we observed sparse covers of erect algae (articulated coralline algae and filamentous turf-forming algae) that formed extensive covers where canopies were absent. Moreover, articulated corallines occurred in greater abundance beneath canopies of E. radiata mixed with canopy-forming species of Fucales than beneath monospecific canopies of E. radiata. We experimentally tested the hypotheses that (1) canopies negatively affect the abundance of articulated corallines and filamentous turfs, (2) physical abrasion of the substratum by canopies contributes to such negative effects, and (3) the effect of abrasion on articulated corallines is greater beneath monospecific canopies than mixed-species canopies, but the effect on filamentous turfs does not differ between types of canopy. Experiments revealed large negative effects of canopies on the abundance of articulated corallines and filamentous turfs, to which abrasion made a substantial contribution ( 54 to $67 \%$ for articulated coralline and $\sim 58 \%$ for filamentous turf). Moreover, the intensity of abrasion was greater beneath monospecific than mixed-species canopies, which was consistent with differences in the effect of canopies and abrasion on articulated corallines (monospecific > mixed-species) but not filamentous turfs (monospecific $=$ mixed-species). Although abrasion is one of many possible influences of algal canopies, our results show that it can substantially contribute to the heterogeneity of understorey habitat on subtidal rocky coasts. Comparison with prior research suggests that the effects of E. radiata canopies on understorey algae may be largely explained by the combined effects of shade, sedimentation and abrasion.
\end{abstract}

KEY WORDS: Abrasion · Ecklonia radiata $\cdot$ Geniculate coralline algae $\cdot$ Kelp forest $\cdot$ Turf-forming algae $\cdot$ Scour

\section{INTRODUCTION}

Many species can directly and indirectly modify the local environment to create conditions that facilitate and exclude other taxa (Jones et al. 1997, Bruno \& Bertness 2001). Patterns of positive and negative associations among organisms are often well understood; they can be repeated with great fidelity and strongly enough to be observable from local $(\mathrm{km})$ to regional scales (1000s of km) (Callaway et al. 2002, Irving et al. 2004). Mechanistically, however, there is often much to learn about the factors that shape and maintain such interactions. Intensive research of positive and negative associations often demonstrates causation through numerous mechanisms that can act in isolation or combination and whose effects may vary across time and space (Callaway 1992, Leonard 1999). An essential prerequisite to such knowledge is to identify relevant factors that contribute to the establishment and maintenance of associations of interest (Leonard 1999, Bruno 2000).

Subtidal rocky coasts at temperate latitudes are characterised by the presence of extensive forests of canopy-forming algae (e.g. kelps) that are widely con- 
sidered heterogeneous systems exhibiting small-scale patchiness in canopy composition (Harrold \& Reed 1985, Dayton et al. 1992). A striking pattern observed around the world is that the type and abundance of understorey algae that occupy space beneath algal canopies often differs greatly from that observed within gaps among canopies (Kennelly 1987, Edwards 1998, Irving et al. 2004). Extensive covers of algae with prostrate forms of growth (e.g. encrusting coralline algae) are frequently associated with canopies of algae (Witman \& Dayton 2001), and may coexist with erect species of algae such as articulated corallines (e.g. California: Dayton et al. 1984, Clark et al. 2004; eastern Australia: Kennelly 1987; NE New Zealand: Schiel 1988; Chile: Santelices \& Ojeda 1984). In other regions, erect algae are sparse beneath canopies and primarily occur within gaps (e.g. western and southern Australia: Melville \& Connell 2001, Irving et al. 2004; United Kingdom: Hawkins \& Harkin 1985, Figueiredo et al. 1996; Italy: Benedetti-Cecchi et al. 2001, Bulleri et al. 2002). Irrespective of their nature, canopyunderstorey associations in algal forests can be repeated with great fidelity across scales of $\mathrm{km}$ to $1000 \mathrm{~s}$ of km (Fowler-Walker \& Connell 2002).

Experimental clearances and additions of algal canopies have demonstrated conspicuous effects on understorey algae, with clearances typically causing understorey assemblages to become similar to those naturally occurring in gaps (and vice versa when canopies are added) (Dayton 1975, Reed \& Foster 1984, Kennelly 1987, Melville \& Connell 2001). Shade afforded by canopies often contributes to an explanation of such responses because it has large effects on understorey taxa that are often consistent with the experimental provision of shade (Kennelly 1989, Duggins et al. 1990, Connell 2003a). In addition, the process of laminae 'sweeping' across the substratum (abrasion) is thought to contribute to the effects of canopies by excluding understorey taxa susceptible to such physical disturbance (Velimirov \& Griffiths 1979, Kennelly 1989). Morphological differences among species of canopy-forming algae mean that not all canopies abrade the substratum (e.g. erect algae with stipes that exceed the length of their laminae; Reed \& Foster 1984). Where abrasion by the canopy does occur, experiments have typically detected strong negative effects on the abundance of mobile invertebrates (e.g. urchins; Konar \& Estes 2003) and the recruitment and survival of sessile invertebrates (e.g. barnacles, serpulid and spirorbid polychaetes; Jenkins et al. 1999, Leonard 1999, River \& Edmunds 2001, Connell 2003b). However, the role of abrasion in shaping abundances of understorey algae remains unclear because of few experimental tests and variation among results. Kennelly's (1989) pioneering research of algal commu- nities demonstrated negligible effects of abrasion by canopies of Ecklonia radiata on several species of understorey algae in the temperate waters of eastern Australia, while Cheroske et al. (2000) detected negative effects of abrasion by canopies of Sargassum spp. on turf-forming algae in the tropical waters of Hawaii.

The rocky subtidal coasts of temperate Australia support extensive covers of the Laminarian alga Ecklonia radiata (C. Agardh) J. Agardh and numerous canopy-forming species of Fucales (Womersley 1987). E. radiata can form dense monospecific stands (typically 0.3 to $2 \mathrm{~m}$ in height; Womersley 1987) or can exist in mixed-species aggregations with species of Fucales (e.g. Cystophora spp., Sargassum spp., Scytothalia dorycarpa; Shepherd \& Womersley 1970, Goodsell et al. 2004). Established canopies are frequently punctuated by gaps where canopy-forming individuals have been removed by disturbance (e.g. storms; Kennelly 1987). Across the western and southern regions of temperate Australia, erect algae such as articulated coralline algae and filamentous turf-forming algae (a complex of closely packed, erect filaments comprising numerous species of algae; sensu Hay 1981) monopolise space within gaps but are sparse beneath canopies (Shepherd \& Womersley 1970, Fowler-Walker \& Connell 2002). Even so, articulated corallines typically form more extensive covers beneath mixed-species than monospecific canopies of E. radiata, although filamentous turfs are conspicuously absent beneath both types of canopy (Irving et al. 2004). Ground-breaking experimental tests of shade provided by E. radiata revealed considerable negative effects on many species of erect algae (Kennelly 1989), which have since been independently supported (Connell 2003a,b). However, Kennelly (1989) also detected negligible effects of abrasion by E. radiata, which is at odds with more recent tests (e.g. negative effects in Connell 2003b).

In this study, we quantified natural associations of articulated coralline algae and filamentous turfforming algae with monospecific canopies of Ecklonia radiata, canopies of $E$. radiata mixed with species of Fucales, and gaps among canopies at our experimental site (West Island, South Australia) and at 4 nearby sites. We then tested the hypotheses that (1) the percentage cover of articulated corallines and filamentous turfs would be negatively affected by canopies (monospecific and mixed-species) if translocated from gaps to beneath canopies, and (2) such negative effects of canopies would be reduced if articulated corallines and filamentous turfs were protected from abrasion beneath the same canopies (i.e. abrasion contributes to the negative effect of canopies). We further tested that (3) the negative effects of canopies, including that of abrasion, would be greater beneath monospecific than 
mixed-species canopies for articulated corallines but would not differ between canopies for filamentous turfs.

\section{MATERIALS AND METHODS}

Natural patterns. Natural differences in the abundance (percentage cover) of articulated corallines and filamentous turfs were quantified among 3 benthic habitats (monospecific canopies of E. radiata, canopies of Ecklonia radiata mixed with species of Fucales, and gaps among canopies; see definitions below) at 5 sites spanning $>50 \mathrm{~km}$ of the coastline of the Fleurieu Peninsula, South Australia, including the site for experimental manipulations (West Island, $35^{\circ} 37^{\prime} \mathrm{S}$, $138^{\circ} 35^{\prime} \mathrm{E}_{\text {; Fig. }}$ 1). All sites supported a mosaic of extensive covers of canopy-forming algae punctuated by gaps among canopies and were of similar exposure to wave energy (i.e. 17 to 22 of 40 sectors ( $9^{\circ}$ each), radiating from the site that are exposed to the open ocean for $7.5 \mathrm{~km}$ or more; see Fowler-Walker et al. 2005a for methods). We identified 3 habitats known to influence the abundance of benthic plants (Irving et al. 2004) and animals (Goodsell et al. 2004) on a scale of $1 \mathrm{~m}^{2}$ as (1) 'monospecific E. radiata' when $\geq 80 \%$ of the canopy cover was E. radiata, (2) 'mixed E. radiata-Fucales' when 40 to $60 \%$ of the canopy cover was E. radiata and the remaining cover consisted of canopy-forming species of Fucales (e.g. Cystophora spp., Sargassum spp., Scytothalia dorycarpa), and (3) 'gaps among canopies' when rocky substrata did not support canopy-forming algae (Goodsell et al. 2004). At each site, quadrats $(0.2 \times 0.2 \mathrm{~m})$ were haphazardly

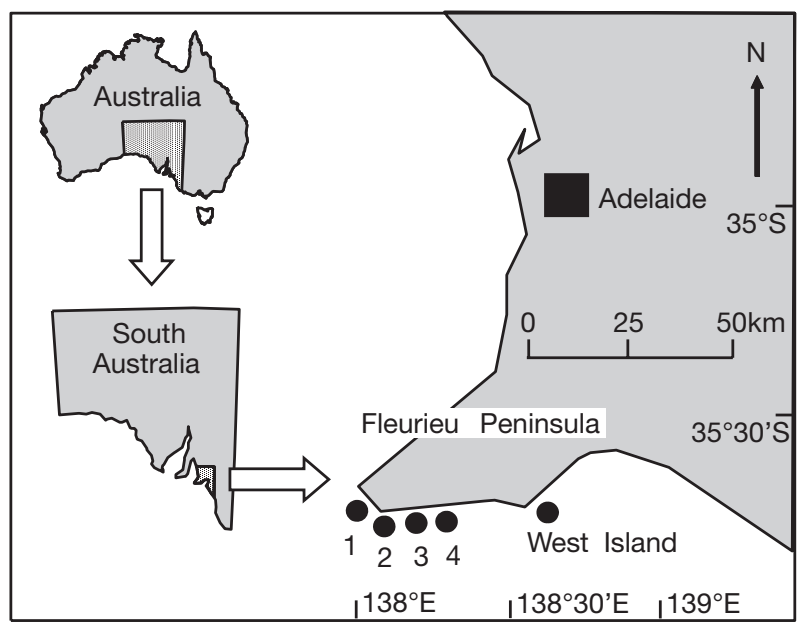

Fig. 1. Locations of study sites along the Fleurieu Peninsula, South Australia, including site of experimental manipulations (West Island). Numbers assigned to sites correspond to those in Fig. 2 placed within patches of each habitat and were positioned $>1 \mathrm{~m}$ from the edge of a patch. The percentage cover of articulated coralline and filamentous turf was quantified using the point-intercept method (25 regularly spaced points within the $0.2 \times 0.2 \mathrm{~m}$ quadrat). Replicates $(\mathrm{n}=8)$ were separated by 1 to $10 \mathrm{~m}$, and sampling was done between depths of 3 and $9 \mathrm{~m}$ at all sites. Differences in the abundance of articulated corallines and filamentous turfs among habitats and sites were tested with ANOVA, treating 'site' as random and 'habitat' as fixed and orthogonal.

Experimental effects of canopies and abrasion. Experimental tests of the effects of canopies and abrasion on articulated corallines and filamentous turfs were done at Abalone Cove, West Island (Fig. 1), using extensive forests of canopy-forming algae and gaps among canopies at depths of $3.03 \pm 0.11 \mathrm{~m}$ (mean $\pm \mathrm{SE}$ depth of replicates). At this site, suitable rocky substrata for the attachment and growth of algae is almost entirely provided by a continuous field of granite boulders ( 0.1 to $0.5 \mathrm{~m}$ diameter) that occur from the intertidal to $\sim 5 \mathrm{~m}$ depth. Very few outcroppings of bedrock exist before boulders give way to extensive sand and seagrass beds (Shepherd \& Womersley 1970).

An orthogonal manipulation of the type of canopy (monospecific vs. mixed-species) and abrasion (presence vs. absence) was used to test (1) the effect of canopies per se, and (2) the effect of abrasion by canopies on the abundance of articulated corallines and filamentous turfs beneath each type of canopy. Small boulders ( 0.2 to $0.3 \mathrm{~m}$ diameter) that naturally supported extensive covers of articulated coralline algae (Haliptilon roseum [Lamarck] Garbary \& Johansen) or filamentous turf-forming algae (primarily a complex of Feldmannia spp., Ectocarpus spp., Sphacelaria spp. and Giffordia spp.; Copertino et al. 2005) were translocated from natural gaps to beneath monospecific and mixed-species canopies ( $\mathrm{n}=15$ boulders each for corallines and turfs). Appropriate treatments were included to test for artifacts of translocation (see below). Beneath each type of canopy, 5 boulders supporting corallines and 5 supporting turfs were exposed to all effects of canopies (including abrasion), while another 5 boulders (corallines and turfs) were protected from abrasion but still exposed to all other effects of canopies (e.g. shade). Abrasion was prevented by caging boulders within $50 \times 50 \mathrm{~mm}$ galvanised mesh to eliminate physical contact between the canopy and experimental boulders. Possible artifacts of the cages were tested by placing the remaining 5 boulders (both coralline and turf beneath each type of canopy) within a partial cage that had elements of the full cage structure but still allowed abrasion (procedural control: a base and 4 sides but no roof). Any differences between the partial cage treatment and 
that where abrasion was allowed (no cage) would suggest an artifact of the cage structure. The same design ( 2 canopy $\times 3$ abrasion treatments) was used to quantify the intensity of abrasion among treatments (see below).

Partial cages are often used to test for artifacts of full cages (e.g. Connell 1997, Leonard 1999), but are not ideal because cage artifacts and manipulated factors (e.g. abrasion) can both occur to some extent in partial cages, but neither occur to the same extent as in fully caged or uncaged treatments (Kennelly 1991). Previous experimental tests of cage artifacts in Ecklonia radiata forests have demonstrated effects on the covers of some sessile invertebrates (e.g. sponges, ascidians), accumulated silt and sediment, but not articulated corallines or filamentous turfs (Kennelly 1989, 1991). Even so, cages that enhance sediment accumulation may indirectly favour articulated corallines and filamentous turfs, which can thrive under such conditions (e.g. Airoldi \& Cinelli 1997). If such indirect caging artifacts occur, covers of these algae should be similar between full and partial cages, yet this result has not been observed previously and was not observed in this study (see 'Results'). We therefore consider partial cages an appropriate method for testing artifacts of full cages on articulated corallines and filamentous turfs in subtidal forests of E. radiata. Full and partial cages were also designed to allow access to small $(<50 \mathrm{~mm})$ benthic herbivores (e.g. gastropods), but probably excluded larger herbivores (e.g. adults of the urchin Heliocidaris erythrogramma). H. erythrogramma, however, are sparsely distributed on the coastline of southern Australia relative to comparable coasts in temperate Australia (e.g. eastern Australia; FowlerWalker \& Connell 2002), and primarily feed on drift algae.

Immediately prior to translocation, the percentage cover of articulated coralline or filamentous turf growing on each boulder was estimated using the pointintercept method (25 regularly spaced points in the central $0.1 \times 0.1 \mathrm{~m}$ of the boulder). Once translocated, we ensured that the upward facing surface of each boulder was positioned the same distance away from the canopy as surrounding boulders by replacing a boulder naturally present beneath the canopy with the experimental boulder (and cage). The percentage cover of algae on each boulder was sampled irregularly throughout the duration of experiment (106 d for articulated corallines, $36 \mathrm{~d}$ for filamentous turfs). Sampling of articulated corallines ended after $106 \mathrm{~d}$ because a storm caused the loss of 2 replicates and also because the experimental effects appeared consistent over the preceding $50 \mathrm{~d}$ (see 'Results'). Sampling of turfs ended after 36 ds because covers were rapidly reduced to $\sim 0 \%$ on boulders exposed to abrasion (see
'Results'), and so no further loss was possible in these treatments. We also sampled key variables (depth, density of Ecklonia radiata and Fucales, length of E. radiata stipe and thallus) among our experimental patches of monospecific and mixed-species canopies because such variables can affect understorey taxa (e.g. Kendrick et al. 1999, Fowler-Walker et al. 2005c) and the intensity of abrasion (Kennelly 1989).

Analyses proceeded in 2 stages. First, the effects of experimental treatments on the cover of corallines and turfs remaining on boulders at the end of the experiment were tested using 2-way ANOVA, treating 'canopy' and 'abrasion' as fixed and orthogonal. These analyses tested the central hypothesis that the effect of abrasion on articulated corallines (but not filamentous turfs) is dependent on the type of canopy. Second, the proportion of the original cover of coralline or turf that was removed by all effects of canopies (i.e. the combined effects of shade, abrasion, sedimentation, flow alteration), and the proportion removed by abrasion alone, were calculated and compared between canopy types. The proportion of the original cover that was removed by canopies was calculated by subtracting the ratio of final:initial cover from 1 in treatments exposed to all effects of canopies (i.e. no cage). The proportion removed by abrasion alone was calculated by (1) subtracting the ratio of final:initial cover from 1 in treatments exposed to all effects of canopies except abrasion (i.e. full cage), and (2) subtracting this value from the proportion removed in treatments exposed to all effects of canopies (no cage; calculated above). Between-canopy differences in the proportion of algae removed by (1) all effects of canopies and (2) abrasion only were tested using 1-way ANOVA, where all data (ratios) were $\log (x)$-transformed prior to analysis (Underwood 1997). Replicates $(n=5)$ for testing the effect of abrasion alone were obtained by randomly pairing the 5 'full cage' replicates with the 5 'no cage' replicates within each type of canopy. We tested 30 different pairing combinations to assess if any single random pairing combination provided representative results.

The process of translocating boulders from gaps to beneath canopies is a physical disturbance that has the potential to affect the abundance of articulated corallines and filamentous turfs, potentially confusing our interpretation of the effects of canopies and abrasion. Hence, all boulders were translocated over similar distances (between 3 and $10 \mathrm{~m}$ ) and care was taken to ensure that the original and final positions of boulders were at similar depths (addition of canopies, of course, was likely to alter factors such as shade and water flow). Nevertheless, we tested for effects of disturbance by (1) lifting 5 boulders supporting corallines and 5 supporting turfs within natural gaps and replac- 
ing them in their original positions (vertical disturbance), and (2) translocating 5 boulders supporting corallines and 5 supporting turfs from natural gaps into other natural gaps located 3 to $10 \mathrm{~m}$ away (horizontal disturbance). The percentage cover of corallines (106 d) and turfs (36 d) on these boulders was compared to that on unmoved boulders (controls) located within gaps. Any differences between moved (lifted or translocated) and unmoved boulders would indicate an effect of translocation.

Assessment of abrasion. Relative differences in the intensity of abrasion beneath monospecific and mixedspecies canopies were tested using 2 methods.

First, following the method of Kennelly (1989), 14 white ceramic tiles $(0.14 \times 0.14 \mathrm{~m})$ were coated with a thin layer of red water-soluble paint and placed beneath monospecific and mixed-species canopies $(\mathrm{n}=$ 7 tiles per type of canopy). Tiles were positioned the same distance away from the canopy as surrounding natural boulders and were exposed to lamina abrasion for $\sim 3 \mathrm{~min}$, after which the percentage of white tile exposed was quantified using the point-intercept method (25 regularly spaced points within the central $0.1 \times 0.1 \mathrm{~m}$ of each tile). Rather than representing the average intensity of abrasion through time, the amount of white tile exposed was used simply as an indicator of the relative intensity of abrasion between monospecific and mixed-species canopies. A further 7 tiles were placed in natural gaps for 3 min to provide an estimate of the dissolution of paint in the absence of abrasion, which instead was presumably due to water motion (flow) over the surface of the tile or sediment scour.

Second, the loss of mass from plaster clods beneath monospecific and mixed-species canopies was tested using the same design as that which tested the effect of canopies and abrasion on corallines and turfs ( 2 canopy $\times 3$ abrasion treatments, $\mathrm{n}=5$ per treatment). Beneath canopies, attributing the loss of plaster to abrasion can be problematic because both abrasion (mechanical removal) and water motion (dissolution) can cause loss of plaster from clods. Hence, we interpret the difference between the amount of plaster lost from clods that were exposed to abrasion (i.e. no cage and partial cage: abrasion and water motion) and those that were protected from abrasion (i.e. full cage: water motion only) as being attributable to abrasion. Partial cages were again used to test for artifacts of cages on the loss of plaster from clods. All clods were made from the same mixture of plaster and were oven-dried at $70^{\circ} \mathrm{C}$ for $48 \mathrm{~h}$ before being weighed. Clods were then placed into appropriate treatments during moderate to strong swell conditions for Abalone Cove $(2 \mathrm{~m}$ swells vs. 0.5 to $1 \mathrm{~m}$ average summer swells, A. D. Irving pers. obs.) and were left for $3 \mathrm{~d}$ before being collected, oven dried $\left(70^{\circ} \mathrm{C}\right.$ for $\left.48 \mathrm{~h}\right)$ and weighed. The amount of plas- ter removed was measured as the percentage loss of mass from each clod. Plaster clods were also placed within natural gaps to indicate the amount of dissolution of plaster in the absence of abrasion but in the presence of water motion. Here, full and partial cages were again used in conjunction with a 'no cage' treatment, with the prediction that the percentage of plaster lost would not differ among the 3 treatments.

\section{RESULTS}

\section{Natural patterns}

At 4 of 5 sites, articulated coralline algae occurred in greater abundance within gaps than beneath canopies but were also more extensive beneath mixed-species than monospecific canopies (Fig. 2a, Table 1) (StudentNewman-Keuls [SNK] tests: gap > mixed > monospecific). At Site 4, similar covers were observed within gaps and beneath mixed-species canopies (i.e. gap = mixed $>$ monospecific). The cover of filamentous turfs was greater within gaps than beneath canopies (i.e. gap $>$ mixed $=$ monospecific) at all sites except Site 2,

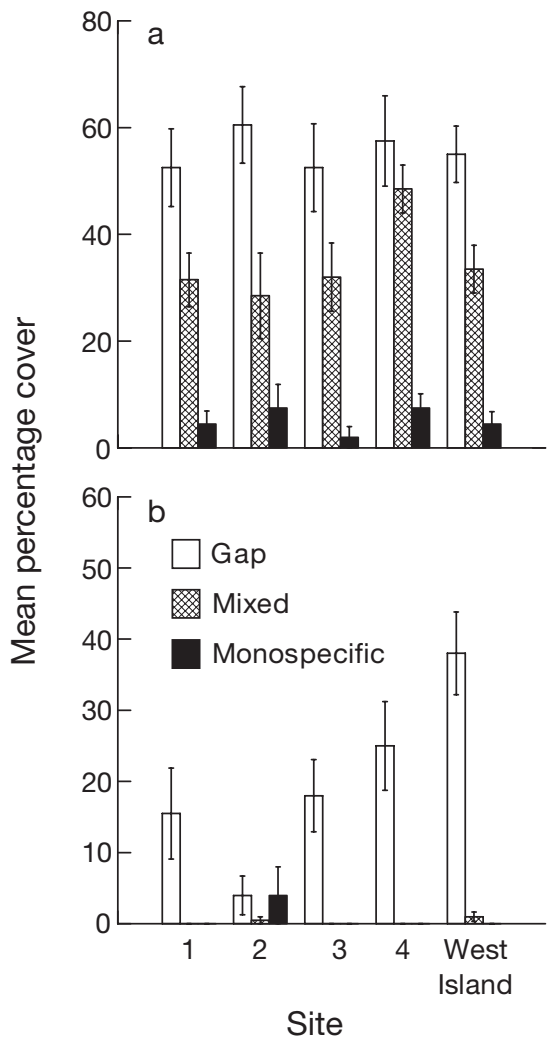

Fig. 2. Natural differences in mean $( \pm \mathrm{SE})$ percentage cover of (a) articulated coralline algae and (b) filamentous turfforming algae among habitats (monospecific vs. mixedspecies vs. gaps) at 5 sites on the coast of South Australia 
Table 1. Results of 2-way ANOVAs testing for differences in percentage cover of articulated coralline algae and filamentous turf-forming algae among habitats (monospecific vs. mixed-species vs. gap) and sites $(\mathrm{n}=5)$ ). Boldface indicates significant effects. Data were arcsine(\%)-transformed. Cochran's $C$-test of homogeneity of variances: $p>0.05$ for articulated coralline algae, and $p<0.05$ for filamentous turfs; hence, significance was judged conservatively ( $\alpha=0.01$ ) for filamentous turfs (Underwood 1997)

\begin{tabular}{|lrrrrrrrr|}
\hline \multirow{2}{*}{ Source } & df & \multicolumn{3}{c}{ Articulated coralline } & \multicolumn{3}{c|}{ Filamentous turf } \\
& & \multicolumn{2}{c}{ MS } & \multicolumn{1}{c}{$F$} & $\mathrm{p}$ & $\mathrm{MS}$ & $F$ & $\mathrm{p}$ \\
\hline Habitat & 2 & 16690.93 & 196.32 & $\mathbf{0 . 0 0 0 0}$ & 5871.02 & 13.99 & $\mathbf{0 . 0 0 2 4}$ \\
Site & 4 & 218.52 & 1.51 & 0.2051 & 331.87 & 4.14 & $\mathbf{0 . 0 0 3 7}$ \\
Habitat $\times$ Site & 8 & 85.02 & 0.59 & 0.7868 & 419.64 & 5.24 & $\mathbf{0 . 0 0 0 0}$ \\
Residual & 105 & 144.89 & & & 80.11 & & \\
\hline
\end{tabular}

Plaster clods that were exposed to abrasion (no cage and partial cage) lost a greater percentage of their original mass than clods protected from abrasion (full cage) beneath monospecific and mixed-species canopies (Fig. 3, Table 2) (abrasion main effect; SNK tests: protected $<$ exposed $=$ procedural control). Differences in the loss of plaster between monospecific and mixedspecies canopies were subtle, but detectable by ANOVA (Table 2: canopy main effect). Clods exposed to abrasion lost a greater percentage of plaster beneath monospecific than mixed-species canopies (SNK tests: monospecific

where no differences among habitats were detected (Fig. 2b, Table 1). Filamentous turfs were almost always absent beneath mixed-species and monospecific canopies, causing heterogeneous variances among treatments even after arcsine (\%) transformation. Analysis proceeded using ANOVA, however, since this procedure is robust to departures from assumptions of homogeneity of variances and normality (Underwood 1997).

\section{Abrasive environment}

The amount of tile exposed (amount of paint removed) was greater beneath monospecific than mixed-species canopies of Ecklonia radiata (ANOVA: $F_{2,12}=75.77, \mathrm{p}<0.001$ ). For this design, such differences between canopies may be caused by differences in ambient water motion, sediment scour, and/ or abrasion by laminae. Experiments were done in shallow water ( $3 \mathrm{~m}$ depth) where wave forces remain strong and are therefore unlikely to differ between canopies. Very little sediment accumulated on tiles or appeared to otherwise remove paint during the $\sim 3$ min that the tiles were placed under canopies. Indeed, paint was observed to be almost exclusively removed by physical contact between the laminae of canopy-formers (E. radiata and species of Fucales) and the surface of the tile, with laterals along the entire length of the thallus appearing capable of removing paint from tiles. Only small amounts of paint were removed within gaps where lamina abrasion does not occur (SNK tests: gap < mixed < monospecific), and was most likely to have been caused by ambient water motion or sediment scour. We therefore consider that differences in the amount of tile exposed between monospecific and mixed-species canopies were primarily caused by differences in the intensity of abrasion by laminae.
$>$ mixed for 'exposed' and 'procedural control' treatments), while clods protected from abrasion lost similar amounts of plaster beneath both types of canopy (Fig. 3). No artifacts of cages were detected (SNK tests: partial cage $=$ no cage). Hence, the difference in the loss of plaster between clods that were protected from vs. exposed to abrasion (i.e. the intensity of abrasion) appears greater beneath monospecific canopies relative to mixed-species canopies. No differences were observed among treatments within gaps (Fig. 3, Gap) (ANOVA: $F_{2,12}=1.16, \mathrm{p}>0.34$ ), suggesting that cages (partial or full) did not alter ambient flow environments or the intensity of sediment scour. Moreover, the amount of plaster lost in gaps was similar to that from clods exposed to abrasion beneath monospecific canopies (Fig. 3). From this result, we predict that the amount of plaster lost due to water motion in gaps is equivalent to the amount lost due to the combined effect of water motion and abrasion beneath monospecific canopies.

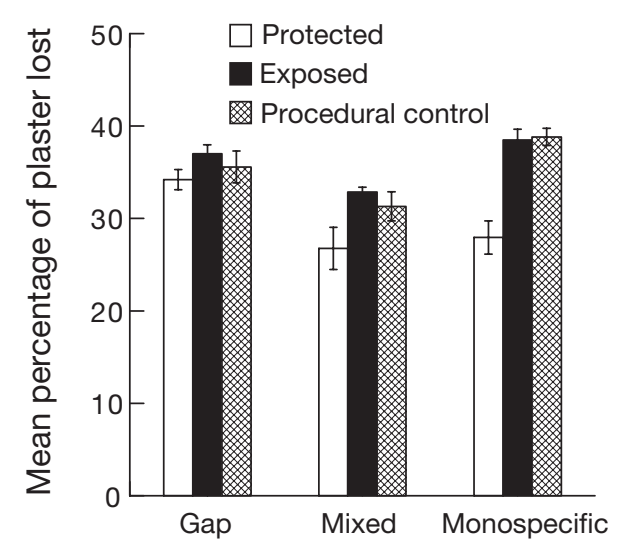

Fig. 3. Mean $( \pm \mathrm{SE})$ percentage loss of mass from plaster clods exposed to and protected from abrasion beneath monospecific and mixed-species canopies, as well as among caging treatments within natural gaps (absence of abrasion) 
Table 2. Results of 2-way ANOVAs testing for effects of abrasion (protected vs. exposed vs procedural control) and type of canopy (monospecific vs. mixed-species) on percentage loss of mass from plaster clods, percentage cover of articulated coralline algae, and percentage cover of filamentous turf-forming algae. Boldface indicates significant effects. Data were arcsine(\%) -transformed. Cochran's $C$-test of homogeneity of variances: $p>0.05$ for all tests

\begin{tabular}{|c|c|c|c|c|c|c|c|c|c|c|}
\hline \multirow[t]{2}{*}{ Source } & \multirow[t]{2}{*}{ df } & \multicolumn{3}{|c|}{ — Plaster clods } & \multicolumn{3}{|c|}{ - Articulated coralline - } & \multicolumn{3}{|c|}{ Filamentous turf } \\
\hline & & MS & F & $\mathrm{p}$ & MS & $F$ & $\mathrm{p}$ & MS & $F$ & $\mathrm{p}$ \\
\hline Abrasion & 2 & 83.08 & 19.41 & 0.0000 & 871.57 & 26.84 & 0.0000 & 4018.24 & 89.66 & 0.0000 \\
\hline Canopy & 1 & 62.99 & 14.72 & 0.0008 & 689.83 & 21.25 & 0.0001 & 0.47 & 0.01 & 0.9189 \\
\hline Abrasion $\times$ Canopy & 2 & 9.25 & 2.16 & 0.1372 & 137.18 & 4.23 & 0.0268 & 21.27 & 0.47 & 0.6278 \\
\hline Residual & 24 & 4.28 & & & 32.47 & & & 44.82 & & \\
\hline
\end{tabular}

\section{Experimental effects on articulated corallines}

At the beginning of the experiment (i.e. immediately prior to translocation: Day 0 in Fig. 4), boulders supported similar covers of articulated coralline algae among treatments $(2$ canopy $\times 3$ abrasion: ANOVA: $\left.F_{2,24}=2.01, \mathrm{p}>0.15\right)$. After 106 days, boulders pro-

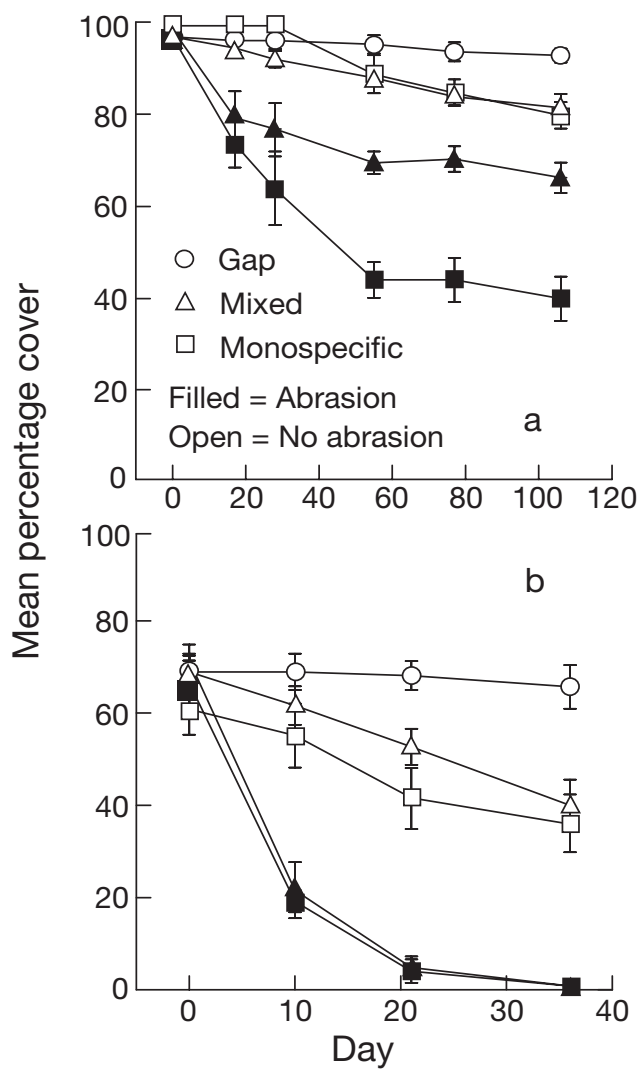

Fig. 4. Mean $( \pm \mathrm{SE})$ percentage cover of (a) articulated coralline algae and (b) filamentous turf-forming algae remaining on boulders within gaps and among experimental treatments of canopy (monospecific vs. mixed-species) and abrasion (exposed vs. protected) through time. Procedural control treatments designed to detect artifacts in the experimental design (cages and translocating boulders) have been omitted because no artifacts were detected tected from abrasion (full cage) still supported extensive covers of articulated coralline that were similar to the covers on boulders that remained within gaps (Fig. 4a). In contrast, the covers of articulated coralline on boulders exposed to abrasion (no cage and partial cage) were reduced relative to boulders protected from abrasion (Fig. 4a, Table 2) (SNK tests: protected > exposed = procedural control, for both monospecific and mixed-species canopies). However, the magnitude of the reduction in the cover of corallines on boulders exposed to abrasion was dependent on the type of canopy (Fig. 4a, Table 2: abrasion $\times$ canopy interaction), being greater beneath monospecific than mixedspecies canopies (SNK tests: monospecific $>$ mixed for exposed and procedural control treatments). Such effects appeared consistent over the final $\sim 50 \mathrm{~d}$ of the experiment (Fig. 4a). Importantly, no artifacts of the cages were detected (exposed = procedural control in all pair-wise comparisons). Likewise, no effect of moving boulders (vertical or horizontal disturbance) was detected for the percentage cover of articulated corallines (ANOVA: $F_{2,12}=1.19, \mathrm{p}>0.30$ ). Hence, the process of translocating boulders from gaps to beneath canopies did not confound interpretation of the observed experimental effects.

The proportion of the original cover of corallines that was removed by all effects of canopies (e.g. shade, abrasion) was greater beneath monospecific than mixed-species canopies (Fig. 5a) (ANOVA: $F_{1,8}=$ $25.32, \mathrm{p}<0.002)$, with $58.71 \pm 4.65 \%$ loss of original cover beneath monospecific canopies and $32.62 \pm$ $2.54 \%$ loss of original cover beneath mixed-species canopies. The contribution of abrasion to the removal of corallines was also greater beneath monospecific than mixed-species canopies (Fig. 5a) (ANOVA: $F_{1,8}=$ $34.04, \mathrm{p}<0.001$ ), with all tests of the 30 different pairing combinations ('full cage' replicates subtracted from 'no cage' replicates) giving this result. Abrasion accounted for $53.60 \pm 7.91 \%$ of the total effect of mixed-species canopies and $66.82 \pm 3.60 \%$ of the total effect of monospecific canopies. 


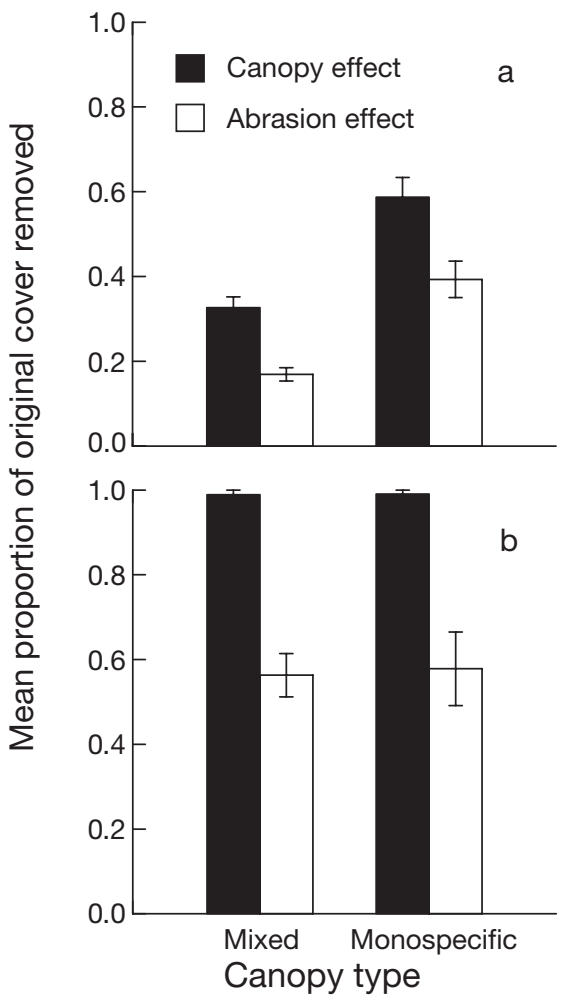

Fig. 5. Mean $( \pm \mathrm{SE}$ ) proportion of original cover of (a) articulated corallines and (b) filamentous turfs removed by all effects of canopies (e.g. shade, abrasion) and abrasion only, beneath mixed-species and monospecific canopies

\section{Experimental effects on filamentous turfs}

All boulders supported similar covers of filamentous turf among treatments at the beginning of the experiment (ANOVA: $F_{2,24}=0.17, \mathrm{p}>0.80$ ). After $36 \mathrm{~d}$, the cover of turfs on all boulders translocated beneath canopies was reduced, while boulders remaining within gaps (controls) still supported extensive covers of turf (Fig. 4b). Boulders exposed to abrasion (no cage and partial cage) lost greater amounts of turf than boulders protected from abrasion (full cage) (Table 2: abrasionmain effect). Notably, this effect was not dependent on the type of canopy (Fig. 4b, Table 2) (non-significant canopy $\times$ abrasion interaction; SNK tests: protected $>$ exposed $=$ procedural control for both monospecific and mixed-species canopies). No differences between 'exposed' and 'procedural control' treatments indicated no artifacts of the cage structures. Again, no effect of moving boulders (vertical or horizontal disturbance) was detected for the percentage cover of filamentous turfs (ANOVA: $F_{2,12}=1.26, \mathrm{p}>0.30$ ).

The negative effect of canopies on filamentous turf was similar between monospecific and mixed-species canopies (Fig. 5b) (ANOVA: $F_{1,8}=0.01, \mathrm{p}>0.90$ ), removing $98.94 \pm 0.70 \%$ of the original cover of turfs on translocated boulders (data pooled across canopies). The contribution of abrasion to the loss of turf on boulders was also of similar magnitude between canopy-types (Fig. 5b) (ANOVA: $F_{1,8}=0.00$, p > 0.90), with all 30 random pairing combinations giving this result. Abrasion accounted for $58.34 \pm 8.57 \%$ of the total effect of monospecific canopies and $57.14 \pm$ $5.80 \%$ of the effect of mixed-species canopies.

\section{Key variables}

No differences in the depth of experimental patches of habitat or the length of the thallus or stipe of Ecklonia radiata were detected between monospecific and mixedspecies canopies (ANOVA: p > 0.05 in all cases). The mean $( \pm \mathrm{SE})$ stipe length and ratio of laminato-stipe length of $E$. radiata in experimental patches were also representative of general measures across $>1000 \mathrm{~km}$ of southern Australian coastline (for this study stipe length $=6.8 \pm 0.9 \mathrm{~cm}$, lamina-to-stipe length ratio $=$ $6.7 \pm 0.5$; cf. general measures discussed in following section). The density of $E$. radiata comprising monospecific canopies was greater $\left(\sim 13\right.$ plants $\left.\mathrm{m}^{-2}\right)$ than that for mixed-species canopies $\left(\sim 7\right.$ plants $\left.\mathrm{m}^{-2}\right)$ (ANOVA: $F_{1,8}=$ 18.99, $\mathrm{p}<0.01)$. Mixed-species canopies also comprised Fucales densities of $\sim 27$ plants $\mathrm{m}^{-2}$.

\section{DISCUSSION}

One of the most striking and frequently cited patterns for temperate rocky coasts around the world is that the type and abundance of understorey algae occupying space beneath canopies of algae differs greatly from that observed within gaps among canopies (e.g. NW Atlantic: Chapman \& Johnson 1990; California: Edwards 1998; Italy: Bulleri et al. 2002; Australia: Fowler-Walker \& Connell 2002). Consistent with this observation, we sampled sparse covers of articulated coralline algae and filamentous turfforming algae beneath algal canopies, but extensive covers within gaps among canopies on subtidal coasts in South Australia (Fig. 2, Table 1). This pattern is similar to observations from other coastlines around the world that also support low densities of benthic herbivores (e.g. urchins) (Hawkins \& Harkin 1985, Bulleri et al. 2002). The experimental addition of canopies had negative effects on the abundance of articulated corallines, and particularly filamentous turfs, which were almost completely removed ( 99\% of original cover) from boulders exposed to all effects of canopies (Fig. 4b, Table 2). However, such negative effects were reduced where abrasion by canopies was prevented. Although abrasion is one of many possible influences 
of canopies, it made a substantial contribution to our observed effects of canopies ( 54 to $67 \%$ for articulated coralline and $\sim 58 \%$ for filamentous turf; Fig. 5). Hence, the negative effect of abrasion by laminae demonstrates that direct physical contact with the benthos, where it occurs (see following discussion), can contribute to the heterogeneity of understorey habitat on subtidal rocky coasts.

The heterogeneous structure of algal forests is often recognised as patchiness associated with the presence and composition of canopies, yet surprisingly few studies have tested for ecological differences between canopies of varying composition (but see Dayton et al. 1984, Clark et al. 2004). We observed that monospecific canopies of Ecklonia radiata had a greater negative effect on the cover of articulated corallines than mixed-species canopies, while negative effects of similar magnitude were observed for both types of canopy for filamentous turfs (Fig. 4, Table 2). Additionally, the intensity of abrasion appears greater beneath monospecific than mixed-species canopies, which is consistent with differences in the effect of abrasion on articulated corallines (monospecific $>$ mixed-species). Although all species of canopy-formers (E. radiata and species of Fucales) were observed to abrade the substratum (see 'Results; Abrasive environment'), it is possible that differences in abrasion intensity are caused by differences in the densities of key species that may exert relatively strong abrasive effects. Even if this model is correct, it does not change the interpretation that clear differences exist in the ecology (patterns and their causes) of monospecific vs. mixedspecies canopies of subtidal algae, and this study contributes to a growing body of knowledge describing such variation (Dayton et al. 1984, Goodsell et al. 2004, Irving et al. 2004).

Qualitative observations of experimental boulders through time suggested mechanistic differences in the way abrasion affected the abundance of articulated corallines and filamentous turfs. Abrasion primarily appeared to affect the abundance of articulated corallines (Haliptilon roseum) through the loss of adventitious branchlets along the lower $2 / 3$ of the thallus to give the alga a more stipitate morphology. The decline in cover seemed to occur uniformly over the surface of boulders subjected to abrasion and exposed either underlying encrusting coralline algae or bare rock. In contrast, the decline in the cover of filamentous turfs appeared to involve the complete removal of thalli (filaments) to expose the underlying bare rock. While such effects also seemed to occur uniformly over the surface of boulders exposed to abrasion, any remaining turf persisted only as a short ( $<5 \mathrm{~mm}$ long) and sparsely distributed 'tuft'. Relative to articulated corallines, a greater magnitude of decline over a shorter period of time was apparent for filamentous turfs.

Experimental tests of abrasion within stands of Ecklonia radiata have revealed intriguing variation among results. In eastern Australia, Kennelly (1989) found abrasion to have negligible effects on several species of understorey algae and sessile invertebrates, while shade from canopies often had large effects. Using a similar experimental design to Kennelly (1989), both Connell (2003b) and the present study detected large negative effects of abrasion on sessile invertebrates (Connell 2003b) and erect algae (present study) in southern Australia. Models to account for such regional inconsistencies are yet to be assessed. A promising model, however, centres on the morphology of E. radiata, which is related to the intensity of abrasion. Using a range of plant sizes, Kennelly (1989) demonstrated that the intensity of abrasion correlates negatively with stipe length. Recent broad-scale sampling of exposed rocky coasts in eastern and southern Australia (32 sites across $>2000 \mathrm{~km}$ of coastline) revealed that E. radiata in eastern Australia generally have longer stipes than plants in southern Australia (mean $\pm \mathrm{SE}=11.0 \pm 0.7 \mathrm{~cm}$ for eastern Australia, $6.7 \pm$ $0.2 \mathrm{~cm}$ for southern Australia), in addition to shorter laminae relative to the stipe length (mean \pm SE laminato-stipe length ratio $=4.5 \pm 0.3$ for eastern Australia, $6.8 \pm 0.4$ for southern Australia) (Fowler-Walker et al. 2005b). The morphology of E. radiata in the present study closely matches these general measures for southern Australia (see 'Results; Key variables'), suggesting that plants in southern Australia are morphologically suitable for exerting strong effects of abrasion. It follows that the intensity of abrasion and its effects on understorey taxa could be less in eastern Australia than in southern Australia because of regional variation in the morphology of E. radiata. Although untested, this model may provide a causative link between a local-scale process (i.e. abrasion) and a regional-scale pattern.

Canopies of algae modify many factors that may contribute to structuring patterns in understorey assemblages. Working in the same algal forest as the present study (West Island), Connell (2003a) observed that the combined effects of shade and sedimentation accounted for $\sim 0.57$ of the effect of monospecific canopies of Ecklonia radiata on understorey algae. Complementing this knowledge, our data estimate the experimental effect of abrasion by monospecific canopies of E. radiata as $\sim 0.39$ (calculated as the average proportion of the original cover of algae that was removed by abrasion alone). Summing these proportions gives a value of $\sim 0.96$, suggesting that the effects of canopies of $E$. radiata on understorey algae may be largely explained by the combined effects of shade, sedimen- 
tation and abrasion. Without appropriate experimental data, this conclusion should be interpreted cautiously, since treatment effects are likely to be interactive and therefore non-additive (e.g. abrasion may also remove accumulated sediment). Also, such conclusions are likely to have spatial limits since $E$. radiata in eastern Australia do not appear to exert strong abrasive effects (Kennelly 1989). Nevertheless, synergistic effects among factors can cause an early divergence in the assembly and subsequent maintenance of understorey associated with the presence and absence of canopies (Connell 2005). Understanding the spatial generality of such synergies remains critical where models are required to predict the response of understorey to the presence (e.g. establishment) and absence (e.g. loss) of algal canopies.

Perhaps the world's best studied subtidal kelp forests are those characterised by Macrocystis pyrifera along the coastline of California. It is useful, therefore, to understand how the ecology of Australian forests compares with these well understood and widely cited habitats. The surface canopy of $M$. pyrifera often occurs above a subsurface canopy formed by species of laminarian algae (mainly Pterygophora californica and several species of Laminaria). These subsurface kelps are of similar size to E. radiata ( 0.5 to $2 \mathrm{~m}$ in length), and their canopies (either alone or in combination with canopies of $M$. pyrifera) reduce ambient light intensity at the substratum to a similar degree, e.g. 91 to $98 \%$ reduction by $P$. californica (Reed \& Foster 1984, Clark et al. 2004) vs. $95 \%$ reduction by E. radiata (Kennelly 1989). In contrast to E. radiata, these subsurface kelps make less physical (abrasive) contact with the substratum (S. D. Connell pers. obs.), and it follows that the understorey within these forests often supports extensive covers of erect algae, especially articulated corallines (Reed \& Foster 1984, Edwards 1998, Clark et al. 2004). Understanding limits of generality between Californian and Australian kelp forests may benefit from realising this physical difference in the kelps themselves.

The challenge of understanding the relative influence of positive and negative interactions in ecology has been revived in recent times (Bruno et al. 2003). Canopies of algae modify local environmental conditions to create favourable habitat for some species (e.g. encrusting coralline algae) but unfavourable habitat for others (e.g. filamentous turfs). Negative effects of abrasion on articulated corallines and filamentous turfs may augment effects of shade provided by canopies, which appear primarily responsible for the maintenance of extensive covers of encrusting coralline algae beneath canopies (Kennelly 1989, Figueiredo et al. 2000, Connell 2003a). Moreover, negative effects of abrasion on corallines and turfs may have indirect positive effects on the abundance of other taxa (e.g. encrusting corallines) by excluding competitors for space and releasing additional resources (e.g. Kastendiek 1982). Experimental tests of fundamental mechanisms to identify variability in the strength of their positive and/or negative effects on key taxa remain vital to improving our knowledge of the maintenance of heterogeneity within these widespread subtidal habitats.

Acknowledgements. We thank T. Elsdon and B. Russell for enthusiastic field assistance, and M. Graham and M. Foster for on-going discussion about the ecology of central Californian kelp. A. Underwood and 2 anonymous reviewers provided constructive feedback that improved the manuscript. This research was supported by a postgraduate award to A.D.I. and an Australian Research Council Discovery grant to S.D.C.

\section{LITERATURE CITED}

Airoldi L, Cinelli F (1997) Effects of sedimentation on subtidal macroalgal assemblages: an experimental study from a Mediterranean rocky shore. J Exp Mar Biol Ecol 215: 269-288

Benedetti-Cecchi L, Pannacciulli F, Bulleri F, Moschella PS, Airoldi L, Relini G, Cinelli F (2001) Predicting the consequences of anthropogenic disturbance: large-scale effects of loss of canopy algae on rocky shores. Mar Ecol Prog Ser 214:137-150

Bruno JF (2000) Facilitation of cobble beach plant communities through habitat modification by Spartina alterniflora. Ecology 81:1179-1192

Bruno JF, Bertness MD (2001) Habitat modification and facilitation in benthic marine communities. In: Bertness MD, Gaines SD, Hay ME (eds) Marine community ecology. Sinauer Associates, Sunderland, MA, p 201-218

Bruno JF, Stachowicz JJ, Bertness MD (2003) Inclusion of facilitation into ecological theory. Trends Ecol Evol 18: 119-125

Bulleri F, Benedetti-Cecchi L, Acunto S, Cinelli F, Hawkins SJ (2002) The influence of canopy algae on vertical patterns of distribution of low-shore assemblages on rocky coasts in the northwest Mediterranean. J Exp Mar Biol Ecol 267: 89-106

Callaway RM (1992) Effect of shrubs on recruitment of Quercus douglasii and Quercus lobata in California. Ecology 73:2118-2128

Callaway RM, Brooker RW, Choler P, Kikvidze Z and 9 others (2002) Positive interactions among alpine plants increases with stress. Nature 417:844-848

Chapman ARO, Johnson CR (1990) Disturbance and organization of macroalgal assemblages in the Northwest Atlantic. Hydrobiologia 192:77-121

Cheroske AG, Williams SL, Carpenter RC (2000) Effects of physical and biological disturbances on algal turfs in Kaneohe Bay, Hawaii. J Exp Mar Biol Ecol 248:1-34

Clark RP, Edwards MS, Foster MS (2004) Effects of shade from multiple kelp canopies on an understorey algal assemblage. Mar Ecol Prog Ser 267:107-119

Connell SD (1997) Exclusion of predatory fish on a coral reef: the anticipation, pre-emption and evaluation of some caging artefacts. J Exp Mar Biol Ecol 213:181-198 
Connell SD (2003a) The monopolization of understorey habitat by subtidal encrusting coralline algae: a test of the combined effects of canopy-mediated light and sedimentation. Mar Biol 142:1065-1071

Connell SD (2003b) Negative effects overpower the positive of kelp to exclude invertebrates from the understorey community. Oecologia 137:97-103

Connell SD (2005) Assembly and maintenance of subtidal habitat heterogeneity: synergistic effects of light penetration and sedimentation. Mar Ecol Prog Ser 289:53-61

Copertino M, Connell SD, Cheshire A (2005) The prevalence and productivity of turf-forming algae on a temperate subtidal coast. Phycologia 44:80-87

Dayton PK (1975) Experimental studies of algal canopy interactions in a sea otter-dominated kelp community at Amchitka Island, Alaska. US Natl Mar Fish Serv Fish Bull 73:230-237

Dayton PK, Currie V, Gerrodette T, Keller BD, Rosenthal R, Ven Tresca D (1984) Patch dynamics and stability of some California kelp communities. Ecol Monogr 54:253-289

Dayton PK, Tegner MJ, Parnell PE, Edwards PB (1992) Temporal and spatial patterns of disturbance and recovery in a kelp forest community. Ecol Monogr 62:421-445

Duggins DO, Eckman JE, Sewell AT (1990) Ecology of understorey kelp environments. II. Effects of kelps on recruitment of benthic invertebrates. J Exp Mar Biol Ecol 143:27-45

Edwards MS (1998) Effects of long-term kelp canopy exclusion on the abundance of the annual alga Desmarestia ligulata (Light F). J Exp Mar Biol Ecol 228:309-326

Figueiredo MAdeO, Kain (Jones) JM, Norton TA (1996) Biotic interactions in the colonisation of crustose coralline algae by epiphytes. J Exp Mar Biol Ecol 199:303-318

Figueiredo MAdeO, Kain (Jones) JM, Norton TA (2000) Responses of crustose corallines to epiphyte and canopy cover. J Phycol 36:17-24

Fowler-Walker MJ, Connell SD (2002) Opposing states of subtidal habitat across temperate Australia: consistency and predictability in kelp canopy-benthic associations. Mar Ecol Prog Ser 240:49-56

Fowler-Walker MJ, Connell SD, Gillanders BM (2005a) To what extent do geographic and associated environmental variables correlate with kelp morphology across temperate Australia. Mar Freshw Res 56:877-887

Fowler-Walker MJ, Connell SD, Gillanders BM (2005b) Variation at local scales need not impede tests for broader scale patterns. Mar Biol 147:823-831

Fowler-Walker MJ, Gillanders BM, Connell SD, Irving AD (2005c) Patterns of association between canopymorphology and understorey assemblages across temperate Australia. Estuar Coast Shelf Sci 63:133-141

Goodsell PJ, Fowler-Walker MJ, Gillanders BM, Connell SD (2004) Variations in the configuration of algae in subtidal forests: implications for invertebrate assemblages. Aust Ecol 29:350-357

Harrold C, Reed DC (1985) Food availability, sea urchin grazing, and kelp forest community structure. Ecology 66: 1160-1169

Hawkins SJ, Harkin E (1985) Preliminary canopy removal experiments in algal dominated communities low on the shore and in the shallow subtidal on the Isle of Man. Bot Mar 28:223-230

Hay ME (1981) The functional morphology of turf-forming seaweeds: persistence in stressful marine habitats. Ecology 62:739-750

Editorial responsibility: Antony Underwood (Contributing Editor), Sydney, New South Wales, Australia
Irving AD, Connell SD, Gillanders BM (2004) Local complexity in patterns of canopy-benthos associations produces regional patterns across temperate Australasia. Mar Biol 144:361-368

Jenkins SR, Norton TA, Hawkins SJ (1999) Settlement and post-settlement interactions between Semibalanus balanoides (L.) (Crustacea: Cirripedia) and three species of fucoid canopy algae. J Exp Mar Biol Ecol 236:49-67

Jones CG, Lawton JH, Shachak M (1997) Positive and negative effects of organisms as physical ecosystem engineers. Ecology 78:1946-1957

Kastendiek J (1982) Competitor-mediated coexistence: interactions among three species of benthic macroalgae. J Exp Mar Biol Ecol 62:201-210

Kendrick GA, Lavery PS, Phillips JC (1999) Influence of Ecklonia radiata kelp canopy on structure of macroalgal assemblages in Marmion Lagoon, Western Australia. Hydrobiologia 398/399:275-283

Kennelly SJ (1987) Physical disturbances in an Australian kelp community. I. Temporal effects. Mar Ecol Prog Ser 40: 145-153

Kennelly SJ (1989) Effects of kelp canopies on understorey species due to shade and scour. Mar Ecol Prog Ser 50: 215-224

Kennelly SJ (1991) Caging experiments to examine the effects of fishes on understory species in a sublittoral kelp community. J Exp Mar Biol Ecol 147:207-230

Konar B, Estes JA (2003) The stability of boundary regions between kelp beds and deforested areas. Ecology 84: 174-185

Leonard GH (1999) Positive and negative effects of intertidal algal canopies on recruitment and survival of barnacles. Mar Ecol Prog Ser 178:241-249

Melville AJ, Connell SD (2001) Experimental effects of kelp canopies on subtidal coralline algae. Aust Ecol 26:102-108

Reed DC, Foster MS (1984) The effects of canopy shading on algal recruitment and growth in a giant kelp forest. Ecology 65:937-948

River GF, Edmunds PJ (2001) Mechanisms of interactions between macroalgae and scleractinians on a coral reef in Jamaica. J Exp Mar Biol Ecol 261:159-172

Santelices B, Ojeda FP (1984) Effects of canopy removal on the understorey algal community structure of coastal forests of Macrocystis pyrifera from southern South America. Mar Ecol Prog Ser 14:165-173

Schiel DR (1988) Algal interactions on shallow subtidal reefs in northern New Zealand: a review. NZ J Mar Freshw Res 22:481-489

Shepherd SA, Womersley HBS (1970) The sublittoral ecology of West Island, South Australia. 1. Environmental features and the algal ecology. Trans R Soc S Aust 94:105-137

Underwood AJ (1997) Experiments in ecology: their logical design and interpretation using analysis of variance, Cambridge University Press, Cambridge

Velimirov B, Griffiths CL (1979) Wave-induced kelp movement and its importance for community structure. Bot Mar 22:169-172

Witman JD, Dayton PK (2001) Rocky subtidal communities. In: Bertness MD, Gaines SD, Hay ME (eds) Marine community ecology. Sinauer Associates, Sunderland, MA, p 339-366

Womersley HBS (1987) The marine benthic flora of Southern Australia. Part II. South Australian Government Printing Division, Adelaide

Submitted: July 12, 2005; Accepted: March 1, 2006

Proofs received from author(s): September 18, 2006 